\title{
Hypothiocyanous acid oxidation of tubulin cysteines inhibits microtubule polymerization
}

\author{
Hillary M. Clark \\ College of William and Mary \\ Tara D. Hagedorn \\ College of William and Mary \\ Lisa M. Landino \\ College of William and Mary
}

Follow this and additional works at: https://scholarworks.wm.edu/aspubs

\section{Recommended Citation}

Clark, H. M., Hagedorn, T. D., \& Landino, L. M. (2014). Hypothiocyanous acid oxidation of tubulin cysteines inhibits microtubule polymerization. Archives of biochemistry and biophysics, 541, 67-73.

This Article is brought to you for free and open access by the Arts and Sciences at W\&M ScholarWorks. It has been accepted for inclusion in Arts \& Sciences Articles by an authorized administrator of W\&M ScholarWorks. For more information, please contact scholarworks@wm.edu. 


\title{
Hypothiocyanous acid oxidation of tubulin cysteines inhibits microtubule polymerization
}

\author{
Hillary M. Clark, Tara D. Hagedorn, Lisa M. Landino* \\ Department of Chemistry, The College of William and Mary, PO Box 8795, Williamsburg, VA 23187-8795, USA
}

\section{A R T I C L E I N F O}

\section{Article history:}

Received 22 August 2013

and in revised form 30 October 2013

Available online 9 November 2013

\section{Keywords:}

Cysteine oxidation

Disulfide

Hypothiocyanous acid

Tubulin

Hypochlorous acid

\begin{abstract}
A B S T R A C T
Thiol oxidation is a probable outcome of cellular oxidative stress and is linked to degenerative disease progression. In addition, protein thiol redox reactions are increasingly identified as a mechanism to regulate protein structure and function. We assessed the effect of hypothiocyanous acid on the cytoskeletal protein tubulin. Total cysteine oxidation by hypothiocyanous and hypochlorous acids was monitored by labeling tubulin with 5 -iodoacetamidofluorescein and by detecting higher molecular weight inter-chain tubulin disulfides by Western blot under nonreducing conditions. Hypothiocyanous acid induced nearly stoichiometric oxidation of tubulin cysteines ( $1.9 \mathrm{~mol}$ cysteine/mol oxidant) and no methionine oxidation was observed. Because disulfide reducing agents restored all the polymerization activity that was lost due to oxidant treatment, we conclude that cysteine oxidation of tubulin inhibits microtubule polymerization. Hypothiocyanous acid oxidation of tubulin cysteines was markedly decreased in the presence of $4 \%$ glycerol, a component of the tubulin purification buffer. Due to its instability and buffer- and pHdependent reactivity, hypothiocyanous acid studies require careful consideration of reaction conditions. (c) 2013 Elsevier Inc. All rights reserved.
\end{abstract}

\section{Introduction}

Our in vitro work with microtubule proteins including tubulin, tau and microtubule-associated protein-2 (MAP-2) shows that cysteine oxidation to disulfides by peroxynitrite anion, hypochlorous acid $(\mathrm{HOCl})^{1}$ and other oxidants is associated with decreased microtubule polymerization [1-3]. Tubulin, a heterodimer composed of similar $50 \mathrm{kDa} \alpha$ - and $\beta$-subunits, contains 20 reduced cysteines (12 in $\alpha$-tubulin and 8 in $\beta$-tubulin) [4,5]. Because some tubulin cysteine oxidation ( $1-2 \mathrm{~mol}$ cys) by oxidants is tolerated before microtubule polymerization is compromised, microtubule protein thiols may protect other cellular targets from oxidation $[1,6]$. This hypothesis is reinforced by our studies showing that the disulfides in tubulin and microtubule-associated proteins are repaired by the thioredoxin and glutaredoxin reductase systems thereby restoring polymerization activity $[1,7]$.

Though present in all cells, tubulin constitutes $10-15 \%$ of total cellular protein in neurons $[8,9]$. Tubulin cysteine modifications including oxidation to disulfides, S-glutathionylation and S-nitrosation, have been identified in several proteomics studies using cell

\footnotetext{
* Corresponding author. Fax: +1 (757) 2212715.

E-mail address: Imland@wm.edu (L.M. Landino).

${ }^{1}$ Abbreviations used: AS, Angeli's salt; BCA, bicinchoninic acid; DTT, dithiothreitol; $\mathrm{GC}$, glycine chloramine; HNO, nitroxyl; HOCl, hypochlorous acid; IAF, 5-iodoacetomido-fluorescein; PB, phosphate buffer; PME, 0.1 M PIPES pH 6.9, 1 mM MgSO, 2 mM EGTA; TCEP, Tris(2-carboxyethyl)phosphine; TNB, thionitrobenzoic acid
}

lines and tissue samples [10-13]. Recently, tubulin was identified as a target for thiol oxidation by $\mathrm{HOCl}$ and chloramines in endothelial cells [14].

In this study, we examine the effects of hypothiocyanous acid (HOSCN) on purified porcine tubulin. HOSCN is a cellular oxidant formed from thiocyanate ion $\left(\mathrm{SCN}^{-}\right)$and $\mathrm{H}_{2} \mathrm{O}_{2}$ by peroxidases including myeloperoxidase (MPO) and eosinophil peroxidase $[15,16]$. HOSCN, like $\mathrm{HOCl}$, oxidizes protein thiols and, if produced in cells, will likely affect tubulin cysteines $[17,18]$. Our current interest in HOSCN is twofold: (1) HOSCN is more selective for cysteines than other oxidants tested. Our published work over the past decade has included oxidants that cause additional types of damage-for example, methionine oxidation, S-nitrosation and tyrosine nitration $[3,6,19]$. While Angeli's salt is largely a cysteine oxidant, presumably via release of HNO, it produces nitrite as a byproduct which could yield nitrosation of cysteines. (2) MPO is aberrantly expressed in Alzheimer's disease brain [20,21]. Moreover, MPO immunoreactivity co-localized with neurofibrillary tangles in neurons of Alzheimer's disease brain and, 3-chlorotyrosine, a marker of $\mathrm{HOCl}$ oxidation was detected. Based on these findings, it is reasonable to hypothesize that $\mathrm{HOSCN}$ and $\mathrm{HOCl}$ could be formed by MPO in AD neurons.

Our focus on tubulin allows us to categorize oxidants with respect to their specificity for cysteine rather than other amino acids. Total cysteine oxidation and effects on microtubule polymerization by $\mathrm{HOSCN}$ and previously characterized oxidants, $\mathrm{HOCl}$, chloramines and Angeli's salt, an HNO donor, are presented [3]. 


\section{Materials and methods}

\section{Materials}

Porcine brains were obtained from Smithfield Packing Company in Smithfield, Virginia. Angeli's salt was from Cayman Chemicals (Ann Arbor, MI). Bicinchoninic acid (BCA) protein assay reagent, West Pico chemiluminescence detection system, Tris(2-carboxyethyl)phosphine (TCEP) and 5-iodoacetomido-fluorescein (IAF) were from Thermo Pierce. The mouse anti- $\beta$-tubulin antibody (clone TUB 2.1) and the goat anti-mouse secondary antibody HRP conjugate were from Sigma. All other chemicals were from Fisher or Sigma. The concentration of $\mathrm{HOCl}$ was determined by measuring the absorbance at $292 \mathrm{~nm}\left(\varepsilon_{292}=350 \mathrm{M}^{-1} \mathrm{~cm}^{-1}\right)$ in $0.1 \mathrm{M} \mathrm{NaOH}$ [22]. A solution of Angeli's salt was prepared immediately prior to use in $0.01 \mathrm{M} \mathrm{NaOH}$ and stored on ice. Glycine chloramine was prepared as described [3].

\section{Preparation of hypothiocyanous acid}

HOSCN was synthesized enzymatically in $0.1 \mathrm{M}$ phosphate buffer $\mathrm{pH}$ 6.4. A typical reaction $(250 \mu \mathrm{l})$ contained $12.5 \mu \mathrm{g}$ LPO, $1.2 \mathrm{mM} \mathrm{KSCN}$ and $\mathrm{H}_{2} \mathrm{O}_{2}$. After $15 \mathrm{~min}$ at $22{ }^{\circ} \mathrm{C}$, the reaction was quenched with $500 \mathrm{U}$ catalase. HOSCN was separated from LPO and catalase using an Amicon Ultra centrifuge filter with a $10 \mathrm{~K}$ cutoff. HOSCN was stored on ice and its concentration was determined using thionitrobenzoic acid (TNB). Under these conditions, the concentration of HOSCN was $225-240 \mu \mathrm{M}$.

\section{Purification of porcine brain tubulin}

Tubulin was purified from porcine brain by two cycles of temperature-dependent polymerization and depolymerization and subsequent phosphocellulose chromatography as described [3].

\section{Labeling of tubulin cysteines with IAF}

Tubulin $(6 \mu \mathrm{M}, 120 \mu \mathrm{M}$ cys $)$ was diluted in either 0.1 M PB pH 7.4 or PME buffer pH 6.9 and then treated with each oxidant for $10 \mathrm{~min}$ at $22^{\circ} \mathrm{C}$ in a total reaction volume of $10-20 \mu$ l. Either methionine or dichlorodimedone $(200 \mu \mathrm{M})$ was added to quench high $\mathrm{HOCl}$ concentrations. IAF $(1.2 \mathrm{mM})$ in DMF was added to achieve a 10-fold molar excess relative to protein cys and samples were incubated at $37^{\circ} \mathrm{C}$ for an additional $30 \mathrm{~min}$. Proteins were resolved by SDS-PAGE on 7.5\% gels under reducing conditions and gel images were captured using a Bio-rad Chemi-doc XRS imaging system. The intensity of the fluorescein-labeled protein bands was measured using Bio-rad Image Lab software. Alternatively, IAFlabeled tubulin was precipitated with $80 \%$ ethanol, incubated on ice for $20 \mathrm{~min}$ and the protein pellet was collected at $16,000 \mathrm{~g}$ for 20 min. Pellets were washed twice with $80 \%$ ethanol and then resuspended in $3 \mathrm{M}$ guanidine $\mathrm{HCl}$ in $0.1 \mathrm{M}$ Tris $\mathrm{pH}$ 8.8. Fluorescein in each protein sample was quantitated at $490 \mathrm{~nm}$ relative to a fluorescein standard curve prepared in $3 \mathrm{M}$ guanidine $\mathrm{HCl}$ in $0.1 \mathrm{M}$ Tris $\mathrm{pH} 8.8$.

\section{Detection of interchain disulfides by Western blot}

Following treatment with oxidants as described above, tubulin species (10-20 $\mu$ g protein per lane) were separated by SDS-PAGE on $7.5 \%$ polyacrylamide gels under nonreducing conditions. Proteins were transferred to PVDF membranes, blocked with $3 \%$ milk for $30 \mathrm{~min}$ and probed with a mouse monoclonal anti- $\beta$-tubulin antibody (1:2000) for two hours. The $\beta$-tubulin/antibody complex was detected using a goat anti-mouse HRP conjugate $(1 \mathrm{~h}$,
1:10,000) and Pierce West Pico chemiluminescent substrate. Chemiluminescence was captured using the Bio-rad Chemi-doc XRS imaging system.

\section{Microtubule polymerization assays}

Purified tubulin, diluted with PME or PB, was treated with up to $75 \mu \mathrm{M}$ oxidant, for $10 \mathrm{~min}$ at $25^{\circ} \mathrm{C}(50 \mu \mathrm{l}, 25 \mu \mathrm{M}$ tubulin, $500 \mu \mathrm{M}$ cys). For repair assays, $1 \mathrm{mM}$ DTT or TCEP was added for an additional $10 \mathrm{~min}$ at $22^{\circ} \mathrm{C}$. GTP ( $1 \mathrm{mM}$ final) was added to induce polymerization and the samples were incubated at $37^{\circ} \mathrm{C}$ for 20 $25 \mathrm{~min}$. Microtubule polymer was collected by centrifugation at $16,000 \mathrm{~g}$ for $20 \mathrm{~min}$. Control polymerization activity was set at $100 \%$ for those samples containing GTP but no oxidant. Controls without GTP were used to establish $0 \%$ activity. Supernatant protein concentrations were determined by the BCA protein assay. Protein supernatants were analyzed by SDS-PAGE with Coomassie Blue staining. Protein pellets were dissolved in $6 \mathrm{M}$ guanidine- $\mathrm{HCl}$ and the absorbance was measured at $275 \mathrm{~nm}$ [1].

\section{CNBr cleavage to detect methionine oxidation}

Tubulin ( $12.5 \mu \mathrm{M}, 250 \mu \mathrm{M}$ cys, $325 \mu \mathrm{M}$ methionine) was treated with each oxidant as described for IAF labeling above. Following acidification to $\mathrm{pH} 2.5$ with $70 \%$ formic acid, samples were treated with 35-40 mM CNBr O.N. Samples were neutralized to $\mathrm{pH}$ 7.4-7.6 with $\mathrm{NH}_{4} \mathrm{OH}$ and subjected to SDS-PAGE under reducing conditions on a $7.5 \%$ polyacrylamide gel. Proteins were transferred to PVDF, blocked with $3 \%$ milk and incubated with mouse anti$\beta$-tubulin (1:2000) for $2 \mathrm{~h}$. The tubulin-antibody complex was visualized using a goat anti-mouse HRP conjugate $(1: 10000,1 \mathrm{~h})$ and a chemiluminescent substrate.

\section{Results and discussion}

\section{IAF labeling of tubulin cysteines}

To assess oxidation of tubulin cysteines, we used the thiolspecific reagent, iodoacetamido-fluorescein (IAF). Because IAF reacts with reduced cysteines only, tubulin labeling will decrease as the dose of oxidant increases. Previous work in our laboratory showed that all 20 cysteines of tubulin, 12 in $\alpha$ - and 8 in $\beta$-tubulin, can be labeled and are accessible without denaturants [1]. Fig. 1A shows that labeling of both $\alpha$ - and $\beta$-tubulin decreased as the concentration of oxidant, $\mathrm{HOSCN}$ or $\mathrm{HOCl}$, increased. This is typical of the oxidants we have studied and no subunit specificity has been observed [3,6,19].

The tubulin preparation used in Figs. 1 and 2 was desalted to remove small molecules present during purification including unbound GTP, glycerol, EGTA and $\mathrm{Mg}^{2+}$. This tubulin was exchanged into PB pH 7.4 because this buffer does not react with oxidants. These methods, including the buffers and ratios of oxidant to tubulin cys are consistent with those we have performed in our studies of tubulin oxidation by $\mathrm{ONOO}^{-}$, $\mathrm{NO}$ donors, $\mathrm{H}_{2} \mathrm{O}_{2}, \mathrm{HOCl}$ and chloramines $[1,3,19,23,24]$.

In Fig. $1 \mathrm{~A}$, tubulin $(120 \mu \mathrm{M}$ cys $)$ was treated with increasing concentrations of $\mathrm{HOCl}$ and $\mathrm{HOSCN}$. As the concentration of oxidant increased, labeling with IAF decreased. Neither thiocyanate ion alone nor decomposed HOSCN affected IAF labeling (Fig. 1S). The concentrations of $\mathrm{HOCl}$ used were greater than those of HOSCN and yet, more oxidation was observed with HOSCN. To ensure that no oxidant remained, we performed time-course experiments with HOSCN and the reaction was essentially complete after 5 min (Supplemental data Fig. 2S). In the case of $100 \mu \mathrm{M}$ HOCl treatment, 
(A)

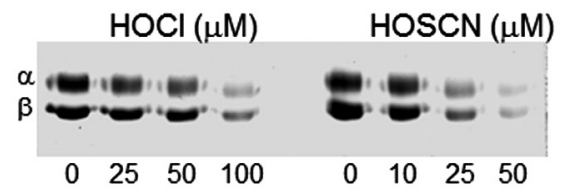

(C)

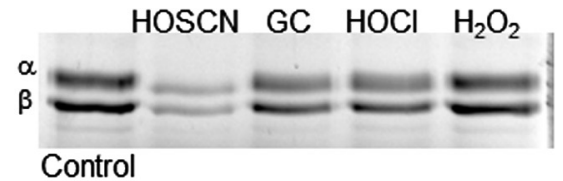

(B)

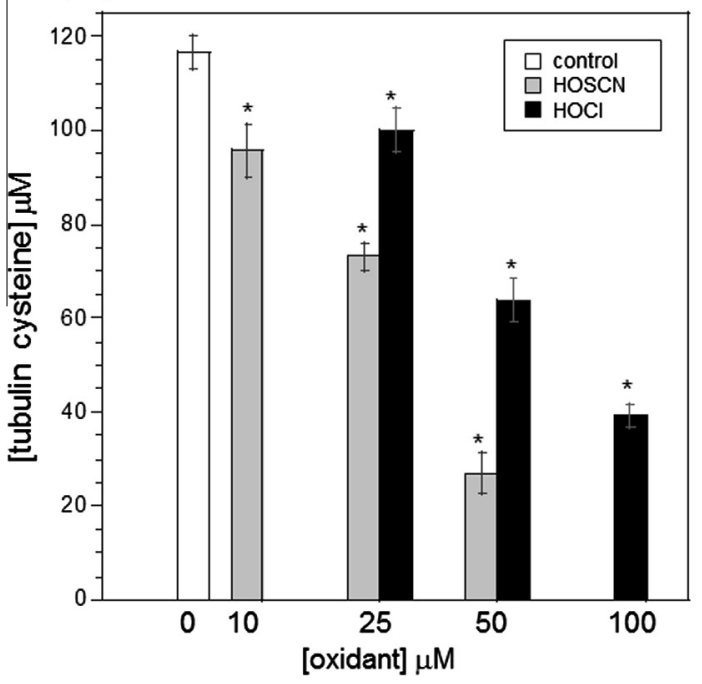

(D)

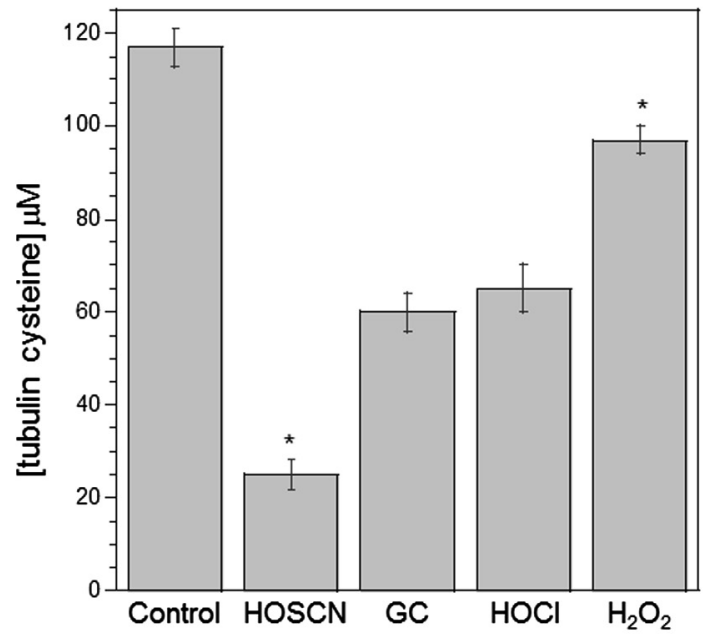

(E)

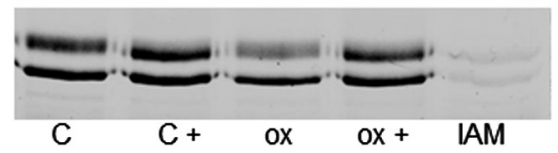

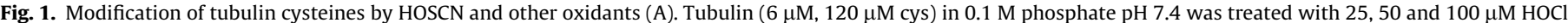

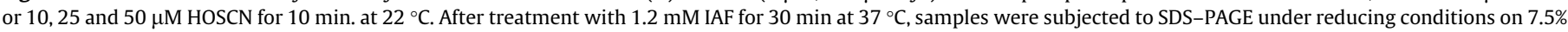

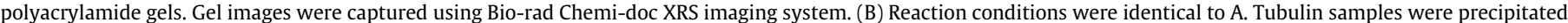

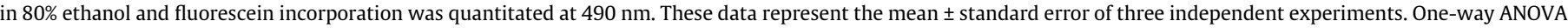

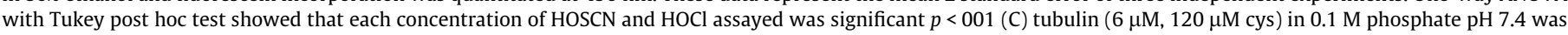

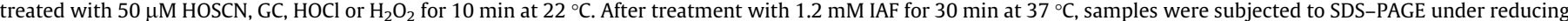

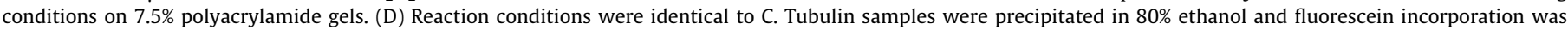

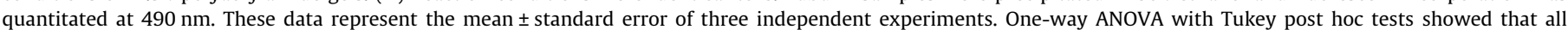

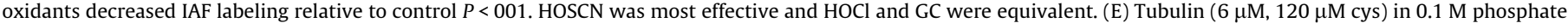

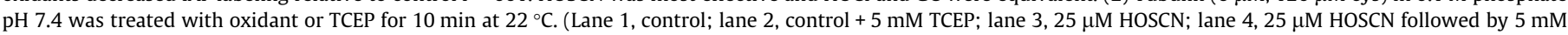

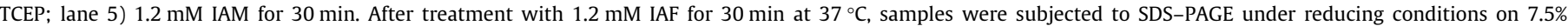
polyacrylamide gels.

$200 \mu \mathrm{M}$ methionine or monochlorodimedone was added to scavenge any remaining oxidant.

Our data is consistent with published work showing that HOS$\mathrm{CN}$ is a more selective cysteine oxidant than $\mathrm{HOCl}[17,18]$. The highest concentration of HOSCN used was $50 \mu \mathrm{M}$ and given the tubulin cysteine concentration $(120 \mu \mathrm{M})$ and the ratio of two cys oxidized per HOSCN, lane eight in Fig. 1A shows nearly stoichiometric cysteine oxidation. We and others have determined that all cysteines of tubulin are accessible to thiol reagents without addition of denaturants [23,24]. Fluorescein incorporation into precipitated tubulin pellets was quantitated at $490 \mathrm{~nm}$ vs. a fluorescein standard curve (Fig. 1B). Using this method and the same concentrations of tubulin and oxidants, 25 and $50 \mu \mathrm{M}$ HOSCN oxidized 46 and $95 \mu \mathrm{M}$ tubulin cys, respectively which is consistent with the IAF labeling in Fig. 1A. Given that HOSCN was always substoichiometric with respect to tubulin cysteines $(50 \mu \mathrm{M}$ HOSCN and $120 \mu \mathrm{M}$ cys), it is unlikely that tryptophan residues of tubulin were oxidized [25]. Given the 1.9:1 stoichiometry (mol cys/mol HOSCN) that is observed, residual RS-SCN would not be expected.

HOSCN was compared to other oxidants that we have examined in addition to $\mathrm{HOCl}$. Fig. 1C shows oxidation of tubulin $(120 \mu \mathrm{M}$ cys) by $50 \mu \mathrm{M}$ HOSCN, glycine chloramine (GC), $\mathrm{HOCl}$ and $\mathrm{H}_{2} \mathrm{O}_{2}$. The concentration of oxidant used was substoichiometric relative to protein cys and no $\mathrm{HOSCN}, \mathrm{HOCl}$ or GC remained in solution after $10 \mathrm{~min}$. In addition to time course experiments, we determined that no oxidant remained using TNB. When TNB was added to the reactions after $10 \mathrm{~min}$, no TNB absorbance change was observed. In the case of $\mathrm{H}_{2} \mathrm{O}_{2}$, catalase was added to ensure that no oxidant remained.

HOSCN was the most effective cysteine oxidant followed by GC/ $\mathrm{HOCl}$ and $\mathrm{H}_{2} \mathrm{O}_{2}$ (Fig. 1C and D). This is consistent with our previous work showing that GC was similar in reactivity to $\mathrm{HOCl}$ with tubulin cysteines [3]. However, we did observe that taurine chloramine was more selective for tubulin cysteines than GC [3]. Peskin and Winterbourn observed that taurine chloramine was a more selective cysteine oxidant than $\mathrm{HOCl}[26,27]$. This ranking of oxidants was confirmed using absorbance data for identical oxidant-treated and IAF-labeled samples that were precipitated with ethanol and resuspended in guanidine $\mathrm{HCl}$ (Fig. 1D). Analysis of the data in Fig. 1D showed no statistical difference between GC and $\mathrm{HOCl}$.

IAF is specific for cysteines and no other amino acids are labeled under the conditions employed (Fig. 1E and Supplemental data 

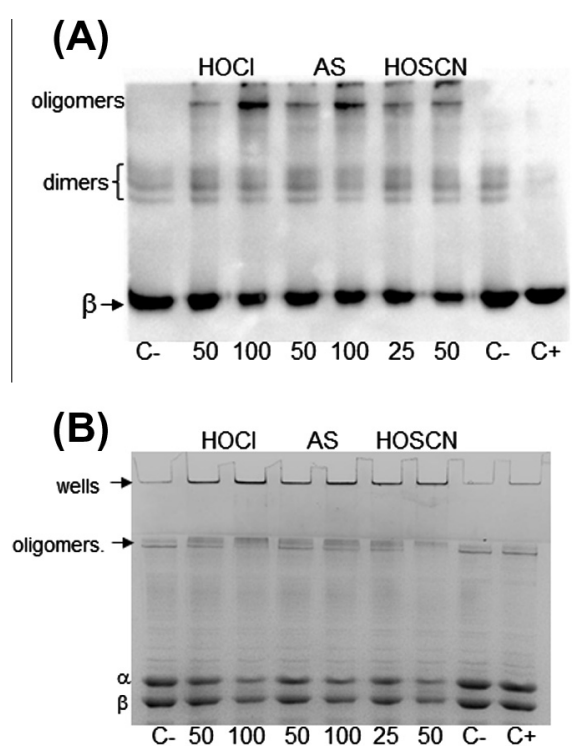

Fig. 2. Detection of higher molecular weight tubulin disulfides by Western blot and Coomassie stain (A). Tubulin ( $10 \mu \mathrm{M}, 200 \mu \mathrm{M}$ cys) was treated with 50 and $100 \mu \mathrm{M}$ $\mathrm{HOCl}$ and Angeli's salt or 25 and $50 \mu \mathrm{M}$ HOSCN for $10 \mathrm{~min}$ at $22^{\circ} \mathrm{C}$. C is control tubulin without a reducing agent whereas $C+$ contained $\beta M E$. For Western blot detection, oxidized tubulin species were separated by SDS-PAGE under nonreducing conditions, transferred to PVDF and probed with anti- $\beta$-tubulin. Monomeric $\beta$-tubulin ( $50 \mathrm{kDa}$ ) is labeled as well as dimers and oligomers. (B) Tubulin samples were identical to those in A. Prior to SDS-PAGE under nonreducing conditions, samples were treated with $50 \mathrm{mM}$ iodoacetamide. Protein bands were stained with Coomassie blue and photographed.

Fig. 3S). The oxidant-induced decrease in IAF labeling that we observed in Fig. 1A-D was reversible when the disulfide reducing agent TCEP was added after oxidant treatment. IAF labeling of oxidized tubulin was restored to control levels by TCEP (Fig. 1E). We chose to use TCEP because it is a phosphine, not a thiol-based reducing agent like DTT. Therefore, it can be present during the IAF labeling step.

In addition, pretreatment of tubulin with iodoacetamide (IAM) abolished IAF labeling (Fig. 1E-lane 5) thereby confirming that IAF is specific for thiols and does not bind nonspecifically to tubulin. An additional IAM-blocking experiment and the corresponding Coomassie-stained gel image are presented in the Supplemental data (Fig. 3S).

\section{Western blot detection of tubulin inter-chain disulfides}

In addition to IAF labeling, we employed a Western blot method to assess cysteine oxidation of tubulin. Oxidation of tubulin cysteines yields higher molecular weight disulfide-linked species that can be resolved by SDS-PAGE under non-reducing conditions. Tubulin dimers and tetramers are formed as well as larger oligomers that do not enter the separating gel. Previous work from our laboratory confirmed that the addition of reducing agents such as $\beta$-mercaptoethanol, DTT and TCEP abolish all higher molecular weight tubulin species including those in the sample wells $[1,6]$.

In Fig. 2A, tubulin ( $200 \mu \mathrm{M}$ cys) was treated with 50 and $100 \mu \mathrm{M} \mathrm{HOCl}$ and Angeli's salt, an HNO donor, and 25 and $50 \mu \mathrm{M}$ HOSCN. As tubulin was oxidized to higher molecular weight species, the $\beta$-tubulin band at $50 \mathrm{kDa}$ decreased in intensity. Likewise the bands observed near the top of the blot increased. This upper band is near the interface of the stacking and separating gels. This top band was not as apparent for tubulin treated with $50 \mu \mathrm{M}$ HOS$\mathrm{CN}$ (lane 6) even though the $50 \mathrm{kDa} \beta$-tubulin band is the lightest on this blot. Additional blots, in which any tubulin in the sample wells was transferred, showed that the greatest $\beta$-tubulin antibody reactivity was in the wells of those samples treated with HOSCN.

Control tubulin in lane 7 of Fig. 2A did not contain a reducing agent whereas control tubulin in lane 8 was treated with DTT. Control tubulin stored in the absence of a reducing agent always contains trace amounts of dimers due to air-oxidation (lane 7) [6]. The two faint dimer bands run at slightly different sizes because brain tubulin is composed of multiple $\alpha$ - and $\beta$-tubulin gene products yielding a heterogeneous mixture of proteins [28].

The greatest extent of tubulin cysteine oxidation to higher molecular weight disulfides was observed with HOSCN even though lower concentrations of $\mathrm{HOSCN}$ were used relative to $\mathrm{HOCl}$ or Angeli's salt. The $\mathrm{HOCl}$ results are consistent with the IAF labeling results in Fig. $1 \mathrm{~A}-\mathrm{D}$. Because changes in the $\beta$-tubulin band intensity at $50 \mathrm{kDa}$ only represent inter-subunit disulfides, it is not possible to quantitate total cysteine oxidation based on the Western blot results. Our qualitative data comparing HOSCN and $\mathrm{HOCl}$ by this method and our quantitative data by IAF labeling demonstrate that HOSCN is a more selective oxidant of cysteine residues in tubulin than $\mathrm{HOCl}$.

\section{Coomassie staining of oxidized tubulin}

Because the Western blot in Fig. 2A only showed oxidation of $\beta$ tubulin, and because Western blots with $\alpha$-tubulin displayed considerable smearing, we have developed another method to assess tubulin cysteine oxidation. Furthermore, we were concerned about antibody binding and effective transfer to PVDF given the formation of very high molecular weight disulfide-linked species following HOSCN treatment.

Tubulin samples were oxidized, treated with IAM to modify any free cysteines and separated by SDS-PAGE under nonreducing conditions. The Coomassie-stained samples in Fig. 2B are identical to those in Fig. 2A. In addition to the $\alpha$ - and $\beta$-tubulin bands which decreased in intensity as oxidation increased, tubulin was detected in the wells of those lanes that contained oxidant-treated tubulin (lanes 1-6). In addition, tubulin was observed at the interface between the stacking and separating gels. This is different from the controls in lanes 7 and 8 where MAP-2, a minor microtubuleassociated protein contaminant was detected. Because both the $\alpha$ - and $\beta$-tubulin bands in Fig. 2B decreased as oxidation increased, both subunits must comprise the higher molecular weight, disulfide-linked tubulin species detected by Western blot in Fig. 2A. Given that the mobility of the MAP2 contaminant also changed, this result suggests that it too is oxidized to higher molecular weight species.

\section{Effect of oxidants on tubulin polymerization}

To assess the effect of oxidants on tubulin polymerization, we oxidized protein samples and then induce polymerization with GTP at $37^{\circ} \mathrm{C}$. Polymerization assays require a much higher concentration of tubulin $(25 \mu \mathrm{M}$ and $500 \mu \mathrm{M}$ cys) relative to the oxidation studies in Figs. 1 and 2 (120-200 $\mu \mathrm{M}$ cys). Furthermore, due to the instability of HOSCN and its relatively low concentration following synthesis, the highest dose of HOSCN and $\mathrm{HOCl}$ tested was $75 \mu \mathrm{M}$. The ratio of oxidant to tubulin cys is important because, in previous work, we determined that some cysteine oxidation is tolerable before polymerization activity is compromised $[1,6]$.

Tubulin polymerization yields a microtubule polymer that can be collected by centrifugation. If polymerization is inhibited by oxidants, the tubulin concentration in the supernatant will increase. In addition, equal volumes of supernatants were subjected to SDS-PAGE with Coomassie staining to determine the extent of 
polymerization. This is especially important if polymerization samples contain reducing agents because they interfere with the BCA assay. Lastly, the amount of microtubule protein in the pellet was measured at $275 \mathrm{~nm}$ and compared to control samples to determine polymerization activity.

Table 1 shows that tubulin treated with $75 \mu \mathrm{M}$ HOSCN and $\mathrm{HOCl}$ resulted in decreased polymerization activity. Inhibition of polymerization by $\mathrm{HOSCN}$ was greater than by $\mathrm{HOCl}$ at both 50 and $75 \mu \mathrm{M}$. However, the difference was minimal with $71 \%$ of control activity in those samples treated with $75 \mu \mathrm{M}$ HOSCN vs. $76 \%$ of control activity in the $75 \mu \mathrm{M} \mathrm{HOCl}$ samples. SDS-PAGE and Coomassie staining of the resulting supernatants consistently showed more protein in the HOSCN samples compared to the $\mathrm{HOCl}$ samples. As expected, the protein pellets obtained for the HOSCNtreated samples contained slightly more protein than the $\mathrm{HOCl}-$ treated samples.

A particular challenge in this work was the comparison of HOS$\mathrm{CN}$ and $\mathrm{HOCl}$ given that HOSCN was synthesized enzymatically in phosphate buffer at $\mathrm{pH}$ 6.4. The lower $\mathrm{pH}$ was required to maximize synthesis of HOSCN; however, tubulin polymerization in vitro is typically performed in PME buffer pH 6.9 [18]. Controls showed that polymerization was reduced in phosphate buffer at all $\mathrm{pH}$ values tested (6.4, 6.9 and 7.4). In addition, the concentration of HOSCN was typically $225-240 \mu \mathrm{M}$ and therefore, relatively large volumes of HOSCN in PB pH 6.4 were combined with tubulin in PME pH 6.9. To correct for these buffer differences, $\mathrm{HOCl}$ was diluted in $\mathrm{PB}$ pH 6.4 and control polymerization assays contained mixtures of PME and PB.

Of note, samples treated with the oxidants and then with DTT prior to the addition of GTP, contained the same amount of pellet protein as controls that did not contain oxidants and DTT. This is important because it shows that reduction of disulfides restored all polymerization activity and that cysteine oxidation was responsible for inhibition. In previous work from our laboratory, higher doses of $\mathrm{HOCl}$ yielded greater cysteine oxidation and lost polymerization activity was not fully restored with a reducing agent [3]. We hypothesized that oxidation and reduction altered protein structure such that some fraction of tubulin was rendered nonfunctional. Thiocyanate ion alone did not inhibit polymerization nor did decomposed HOSCN.

Given the results in Figs. 1 and 2 confirming that HOSCN is a much more effective cysteine oxidant than $\mathrm{HOCl}$, the polymerization results in Table 1 were perplexing. Careful consideration of the tubulin preparations used in Figs. 1 and 2 vs. Table 1 suggested a possible explanation. Tubulin is purified from brain tissue by cycles of temperature-dependent polymerization and depolymerization followed by phosphocellulose column chromatography to remove microtubule-associated proteins. In addition to PME buffer, some GTP and glycerol is present following purification. It is this PME-tubulin that was used for polymerization assays whereas portions of PME-tubulin were desalted into

\section{Table 1}

Effect of $\mathrm{HOSCN}$ and $\mathrm{HOCl}$ on cysteine oxidation and microtubule polymerization. Polymerization assays contained $25 \mu \mathrm{M}$ tubulin ( $500 \mu \mathrm{M}$ cys) and $75 \mu \mathrm{M}$ oxidant in PME-tubulin. Cysteine oxidation of PB-tubulin was assessed by IAF labeling as described in Fig. 1 using $100-150 \mu \mathrm{M}$ tubulin cys and up to $75 \mu \mathrm{M}$ oxidant. PMEtubulin was diluted to the same ratio of tubulin cys to oxidant. Band intensities were used to calculate mol cys/mol oxidant.

\begin{tabular}{llll}
\hline Oxidant & \% Polymerization activity & \multicolumn{2}{l}{$\begin{array}{l}\text { Cysteine oxidation (mol cys/mol } \\
\text { oxidant) }\end{array}$} \\
\cline { 3 - 4 } & & PB-tubulin & PME-tubulin \\
\hline HOSCN & $71 \pm 3$ & $1.9 \pm 0.1$ & $1.2 \pm 0.2$ \\
HOCl & $76 \pm 2$ & $0.9 \pm 0.2$ & $1.0 \pm 0.2$ \\
\hline
\end{tabular}

phosphate buffer $\mathrm{pH} 7.4$ for the assays in Figs. 1 and 2 (PB-tubulin).

To address this discrepancy, we treated PME-tubulin, used for polymerization assays, with $\mathrm{HOSCN}$ and $\mathrm{HOCl}$ using the same protein to oxidant ratio as employed in our polymerization studies (Table 1). The IAF labeling results showed that both HOSCN and $\mathrm{HOCl}$ oxidized cysteines; however, the differences between the two oxidants are not as striking as in Fig. 1A-D). Quantitation of band intensities showed that $75 \mu \mathrm{M}$ HOSCN oxidized $1.2 \mathrm{~mol}$ cys/ mol oxidant whereas $75 \mu \mathrm{M} \mathrm{HOCl}$ oxidized $1.0 \mathrm{~mol}$ cys $/ \mathrm{mol}$ oxidant.

\section{Buffer and glycerol effects on HOSCN oxidation of tubulin}

To determine which component of the PME-tubulin preparation interfered with cysteine oxidation by HOSCN, we systematically added the buffer components: PIPES, $\mathrm{Mg}^{2+}$ and EGTA to PB-tubulin prior to the addition of HOSCN. In addition, we tested the ability of GTP and glycerol to infer with tubulin cysteine oxidation by HOSCN.

Although a slight difference in oxidation was observed with PIPES vs. PB, the presence of as little as $1.5 \%$ glycerol decreased HOSCN oxidation of tubulin in PME. These results are shown in Fig. 3A. The samples in lanes 1-4 contained tubulin in PB whereas those in lanes 5-8 contain tubulin in a mixture of phosphate and PIPES buffers. Greater oxidation of tubulin by HOSCN is observed in lane 6 for the PIPES/phosphate sample vs. the phosphate-only sample in lane 2 indicative of a buffer effect. This is not unexpected given that HOSCN is unstable and its half-life varies in a $\mathrm{pH}$ dependent manner $[15,17,29]$. Tubulin samples in lanes 7 and 8 were identical to lane 6 except they contained $1.5 \%$ and $4 \%$ glycerol, respectively. The much darker $\alpha$ - and $\beta$-tubulin bands are indicative of less tubulin oxidation to higher molecular weight species. For the tubulin samples oxidized by HOSCN in phosphate buffer (lanes 2-4), the $4 \%$ glycerol sample showed decreased tubulin cysteine oxidation (lane 4 ) but the $1.5 \%$ sample had only a modest effect.
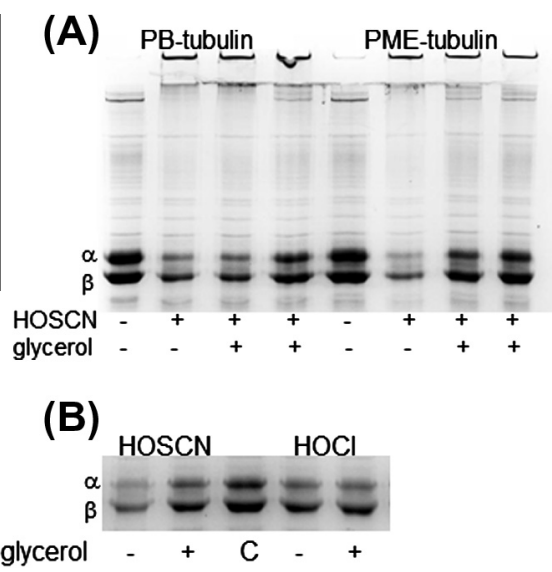

Fig. 3. Effect of buffer and glycerol on tubulin cysteine oxidation by HOSCN and $\mathrm{HOCl}$ (A). Tubulin ( $6 \mu \mathrm{M}, 120 \mu \mathrm{M}$ cys) was treated with $25 \mu \mathrm{M}$ HOSCN in $0.1 \mathrm{M}$ phosphate $\mathrm{pH} 7.4$ (lanes 1-4) or phosphate plus PME (lanes 5-8) for $10 \mathrm{~min}$ at $22{ }^{\circ} \mathrm{C}$. In addition to HOSCN, samples in lanes 3 and 7 contained $1.5 \%$ glycerol whereas those in lanes 4 and 8 contained $4 \%$ glycerol. Controls are shown in lanes 1 and 5. (B) Tubulin ( $6 \mu \mathrm{M}, 120 \mu \mathrm{M}$ cys) was treated with $50 \mu \mathrm{M}$ HOSCN (lane1) or $\mathrm{HOCl}$ (lane 4) in $0.1 \mathrm{M}$ phosphate $\mathrm{pH} 7.4$ for $10 \mathrm{~min}$ at $22^{\circ} \mathrm{C}$. Samples in lanes 2 and 5 contained $4 \%$ glycerol in addition to oxidant. C is control tubulin. Prior to SDSPAGE under nonreducing conditions on $7.5 \%$ gels, samples were treated with $50 \mathrm{mM}$ iodoacetamide. Protein bands were stained with Coomassie blue and photographed. 
We hypothesized that glycerol decreased tubulin oxidation by HOSCN due to changes in solution viscosity and hydrogen-bonding capacity. Alterations in hydrogen-bonding networks on the surface of tubulin by glycerol could limit accessibility to thiols by oxidants and labeling reagents. Because HOSCN is a short-lived oxidant with a half-life of $42 \mathrm{~min}$ at $\mathrm{pH} 6.5$, it is possible that glycerol impedes its interaction with tubulin cysteines [17,29].

Experiments with TNB, a small molecule thiol, were performed to determine if glycerol decreased HOSCN oxidation. No glycerol effect was observed with up to $10 \%$ glycerol. However, $4 \%$ glycerol hindered control IAF labeling of cysteines in the model proteins, glyceraldehyde-3-phosphate dehydrogenase (GAPDH) and creatine kinase. IAF labeling of control GAPDH and creatine kinase decreased by $23 \%$ and $20 \%$, respectively in the presence of $4 \%$ glycerol (Supplemental data Fig. 4S). While it is clear that IAF labeling of unoxidized GAPDH and creatine kinase was affected by $4 \%$ glycerol, interpretation of changes in HOSCN oxidation are unclear.

To confirm a glycerol effect for $\mathrm{HOSCN}$, but not for $\mathrm{HOCl}$, we treated tubulin with each oxidant in the presence and absence of $4 \%$ glycerol. Fig. 3B clearly shows the difference in tubulin oxidation by HOSCN when glycerol was present (lanes 1 vs. 2). However, no appreciable difference in tubulin oxidation by $\mathrm{HOCl}$ was observed in lanes 3 vs. 4 . This result is consistent with the data in Table 1 showing nearly equivalent cysteine oxidation of PMEtubulin and correspondingly similar inhibition of tubulin polymerization by the two oxidants.

\section{Cyanogen bromide cleavage assay to detect methionine oxidation}

We had previously shown that $\mathrm{HOCl}$ and chloramines oxidized tubulin methionines using a cyanogen bromide ( $\mathrm{CNBr}$ ) cleavage assay [3]. Therefore we wanted to confirm that tubulin methionines were not oxidized by HOSCN. Controls were performed in the presence of excess thiocyanate to ensure that the ion did not interfere with $\mathrm{CNBr}$ cleavage. Tubulin treated with HOSCN was fragmented to the same extent as tubulin that had not been oxidized (Fig. 4).

While it is apparent that HOSCN does oxidize tubulin cysteines, the kinetics and $\mathrm{pH}$ dependence of the reaction are complex. Kinetic data shows that $\mathrm{HOSCN}$, not ${ }^{-} \mathrm{OSCN}$, reacts with protein thiolates (RS ${ }^{-}$) [17]. Given that the HOSCN pK $\mathrm{a}$ is $\sim 5$ (both 5.3 and 4.85 have been reported) and most thiols have $\mathrm{pK}_{\mathrm{a}}$ values of $8-9$, $\mathrm{pH}$, buffer choice and even ionic strength can have a great effect on HOSCN reactivity $[15,17]$. Furthermore, HOSCN is unstable and decomposes with $\mathrm{pH}$-dependent half-life of $42.5 \mathrm{~min}$ at $\mathrm{pH}$ 6.5 [29].

All 20 cysteines of tubulin 12 in $\alpha$ - and 8 in $\beta$-tubulin, can be labeled by thiol reagents $[23,24]$. However, no detailed study of their $\mathrm{pK}_{\mathrm{a}}$ values has been reported and it is assumed that $\mathrm{pK}_{\mathrm{a}}$ values are typical of the amino acid cysteine ( 8.5-9). Of note, Britto et al. have identified two classes of tubulin cysteines, slow- and fast-reacting but they could not be distinguished with iodoacetamide-based reagents. Further, Britto et al. examined the $3.5 \AA$

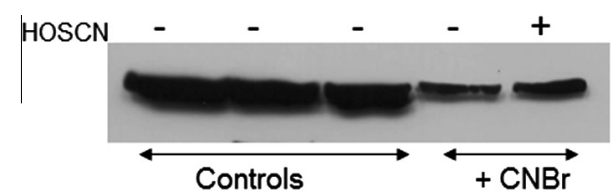

Fig. 4. $\mathrm{CNBr}$ cleavage assay to detect methionine oxidation. Tubulin (12.5 $\mu \mathrm{M}$, $250 \mu \mathrm{M}$ cys, $325 \mu \mathrm{M}$ methionine) samples were treated as follows: Lane 1: control tubulin; lane 2: tubulin + formic acid and $\mathrm{NH}_{4} \mathrm{OH}$; lane 3: tubulin + $500 \mu \mathrm{M} \mathrm{KSCN}$, formic acid and $\mathrm{NH}_{4} \mathrm{OH}$; lane 4: tubulin + formic acid, $\mathrm{CNBr}$, and $\mathrm{NH}_{4} \mathrm{OH}$; lane 5: tubulin $+100 \mu \mathrm{M}$ HOSCN, formic acid, $\mathrm{CNBr}$, and $\mathrm{NH}_{4} \mathrm{OH}$. Samples were separated by SDS-PAGE under reducing conditions, transferred to PVDF and probed with anti$\beta$-tubulin. electron diffraction structure of tubulin and identified some positively charged amino acids in proximity to cysteines [23]. They hypothesize that such a positive charge could stabilize a thiolate thereby enhancing reactivity with electrophiles and possibly with oxidants.

Our results herein and in previous work do not support selective oxidation of tubulin cysteines. We routinely check for selectively with each oxidant by trypsin digestion of IAF-labeled tubulin. We observe that as the concentration of oxidant increases, all IAF labeled peptide peaks decrease suggesting partial oxidation, and therefore similar reactivity of tubulin cysteines.

HOSCN is the most selective tubulin cysteine oxidant we have identified to date. Of all the oxidants we have tested previously, only Angeli's salt, an HNO donor, is specific for cysteine. However, the rate of HNO release is also dependent on reaction conditions and the half-life of Angeli's salt is only $2.3 \mathrm{~min}$ at $37^{\circ} \mathrm{C}$ in $0.1 \mathrm{M}$ phosphate buffer $\mathrm{pH} 7.4$ [30]. Thus, the effective dose of HNO from Angeli's salt is dependent on reaction conditions. Given that all the oxidants tested have the potential to form in cells, our findings are important in both understanding the outcome of cellular oxidative stress and in understanding tubulin reactivity in vitro.

\section{Acknowledgment}

The authors acknowledge support from the National Institute of Neurological Disorders and Stroke (R15-NS38885 to LML).

\section{Appendix A. Supplementary data}

Supplementary data associated with this article can be found, in the online version, at http://dx.doi.org/10.1016/j.abb.2013.10.026.

\section{References}

[1] L.M. Landino, J.S. Iwig, K.L. Kennett, K.L. Moynihan, Free Radical Biology \& Medicine 36 (2004) 497-506.

[2] L.M. Landino, T.E. Skreslet, J.A. Alston, Journal of Biological Chemistry 279 (2004) 35101-35105.

[3] L.M. Landino, T.D. Hagedorn, S.B. Kim, K.M. Hogan, Free Radical Biology \& Medicine 50 (2011) 1000-1008.

[4] E. Nogales, S.G. Wolf, K.H. Downing Nature 391 (1998) 199-203.

[5] R.F. Luduena, M.C. Roach, Pharmacological \& Therapeutics 49 (1991) 133-152.

[6] L.M. Landino, R. Hasan, A. McGaw, S. Cooley, A.W. Smith, K. Masselam, G. Kim, Archives of Biochemistry and Biophysics 398 (2002) 213-220.

[7] L.M. Landino, K.L. Moynihan, J.V. Todd, K.L. Kennett, Biochemical and Biophysical Research Communications 314 (2004) 555-560.

[8] J.B. Olmsted, Journal of Cell Biology 89 (1981) 418-423.

[9] P.J. Anderson, Journal of Biological Chemistry 254 (1979) 2168-2171.

[10] R.C. Cumming, N.L. Andon, P.A. Haynes, M. Park, W.H. Fischer, D. Schubert Journal of Biological Chemistry 279 (2004) 21749-21758.

[11] R. Pamplona, E. Dalfo, V. Ayala, M.J. Bellmunt, J. Prat, I. Ferrer, M. Portero-Otin, Journal of Biological Chemistry 280 (2005) 21522-21530.

[12] J.P. Brennan, R. Wait, S. Begum, J.R. Bell, M.J. Dunn, P. Eaton, Journal of Biological Chemistry 279 (2004) 41352-41360.

[13] M. Sparaco, L.M. Gaeta, G. Tozzi, E. Bertini, A. Pastore, A. Simonati, F.M. Santorelli, F. Piemonte, Journal of Neuroscience Research 83 (2006) 256-263.

[14] F.A. Summers, A.F. Quigley, C.L. Hawkins, Biochemical and Biophysical Research Communications 425 (2012) 157-161.

[15] T.J. Barrett, C.L. Hawkins, Chemical Research in Toxicology 25 (2011) 263-273.

[16] A.E. Lane, J.T.M. Tan, C.L. Hawkins, A.K. Heather, M.J. Davies, Biochemical Journal 430 (2010) 161-169.

[17] P. Nagy, G.N.L. Jameson, C.C. Winterbourn, Chemical Research in Toxicology 22 (2009) 1833-1840.

[18] O. Skaff, D.I. Pattison, M.J. Davies, Biochemical Journal 422 (2009) 111-117.

[19] L.M. Landino, M.T. Koumas, C.E. Mason, J.A. Alston, Chemical Research in Toxicology 20 (2007) 1693-1700.

[20] P.S. Green, A.J. Mendez, J.S. Jacob, J.R. Crowley, W. Growdon, B.T. Hyman, J.W. Heinecke, Journal of Neurochemistry 90 (2004) 724-733.

[21] R.A. Maki, V.A. Tyurin, R.C. Lyon, R.L. Hamilton, S.T. DeKosky, V.E. Kagan, W.F. Reynolds, Journal of Biological Chemistry 284 (2009) 3158-3169.

[22] C.C. Winterbourn, S.O. Brennan, Biochemical Journal 326 (1997) 87-92.

[23] P.J. Britto, L. Knipling, P. McPhie, J. Wolff, Biochemical Journal 389 (2005) 549558.

[24] P.J. Britto, L. Knipling, J. Wolff, Journal of Biological Chemistry 277 (2002) 29018-29027. 
[25] C.L. Hawkins, D.I. Pattison, N.R. Stanley, M.J. Davies, Biochemical Journal 416 (2008) 441-452.

[26] A.V. Peskin, C.C. Winterbourn, Free Radical Biology \& Medicine 30 (2001) 572 579.

[27] A.V. Peskin, C.C. Winterbourn, Free Radical Biology \& Medicine 40 (2006) 4553.
[28] R.F. Luduena, International Review of Cytology 178 (1998) 207-275.

[29] P. Nagy, S.S. Alguindigue, M.T. Ashby, Biochemistry 45 (2006) 12610-12616.

[30] C.M. Maragos, D. Morley, D.A. Wink, T.M. Dunams, J.E. Saavedra, A. Hoffman, A.A. Bove, L. Isaac, J.A. Hrabie, L.K. Keefer, Journal of Medicinal Chemistry 34 (1991) 3242-3247. 